\title{
Modification of Starch Composition Using RNAi Targeting Soluble Starch Synthase I in Japonica Rice
}

\author{
Hye Jung Lee ${ }^{1 \S}$, Moo-Geun Jee ${ }^{1 \S}$, Joonki Kim ${ }^{1}$, Franz M.C. Nogoy ${ }^{1}$, Marjohn C. Niño ${ }^{1}$, Dal-A Yu ${ }^{1}$, Me Sun Kim ${ }^{1}$, \\ Mingmao Sun ${ }^{1,2}$, Kwon-Kyoo Kang ${ }^{3}$, Illsup Nou ${ }^{4}$, Yong-Gu Cho ${ }^{1 *}$ \\ ${ }^{1}$ Dept. of Crop Science, Chungbuk National University, Cheongju 361-763, Korea \\ ${ }^{2}$ Biological Engineering R\&D Center, Weifang University of Science \& Technology, Shouguang 262700, China \\ ${ }^{3}$ Dept. of Horticulture, Hankyong National University, Ansung 456-749, Korea \\ ${ }^{4}$ Dept. of Horticulture, Sunchon National University, Sunchon 540-742, Korea
}

\begin{abstract}
An increasing preference for good eating quality of rice among consumers has become one of the important considerations in rice breeding. Amylose content is a leading factor affecting eating quality of rice. Amylose composition is determined by the relative activity of soluble starch synthase (SSS) and granule-bound starch synthase (GBSS). This study focused on modifying the expression of SSSI gene which is responsible for amylopectin and amylose synthesis in rice by using RNA interference (RNAi) technology. The transgenic rice plants showed various amylose contents (11-17\%) in rice grains. Favorable rice lines were selected according to genomic PCR, transgene expression and amylose contents analysis. A semi-quantitative RT-PCR was carried out to determine the expression level of SSSI gene after flowering of transgenic rice and wild type. Down-regulation of SSSI gene in transgenic plants was evident in the decreasing expression in rice grains. Accordingly, scanning electron microscopy (SEM) analysis revealed uniform size with smooth curves starch granules in down-regulation rice lines, in contrast with the non-uniform granules in wild type. Results indicated that RNAi-SSSI transgenic lines produced low amylose contents that fell between glutinous and non-glutinous rice. This study showed that down-regulation of endogenous SSSI may improve the eating quality in rice.
\end{abstract}

Keywords Japonica rice, RNAi, Rice eating quality, Soluble Starch Synthase I, Starch

\section{INTRODUCTION}

Cooking and eating quality is one of the important components of grain quality. Based on the knowledge accumulated in the past, cooking and eating quality is directly related to three attributes of the physical and chemical characteristics of starch in endosperm namely, amylose content (AC) (Tan et al. 1999), gel consistency (GC) (Cagampang et al. 1973), and gelatinization temperature (GT) (Little et al. 1958).

The starch in rice endosperm generally consists of D-glucose homopolymers, amylose and amylopectin (Juliano and Perez 1983). Rice is categorized depending on amylose content into four groups, waxy (0-5\%), low amylose (7-20\%), middle amylose $(21-25 \%)$ and high amylose $(>25 \%)$.
Furthermore, the composition of amylopectin is crucial to rice eating quality under certain threshold of protein content as well as the ratio of amylose to amylopectin (Lestari et al. 2009). As one of the important factors determining rice palatability, amylopectin content is conversely affected by the amount of amylose. Amylopectin composition is determined by the relative activity of soluble starch synthase (SSS) and granule-bound starch synthase (GBSS), which are related to the chain elongation of amylopectin and amylose, respectively (Nakamura et al. 2005).

Soluble starch synthase is a major derivative for the synthesis of amylopectin. There are four types of SSS, such as SSSI, SSSII, SSSIII, and SSSIV, and some types have multiple isoforms according to plant species. Rice has a total of eight isoforms of SSS encoded by independent

Received September 26, 2014; Revised September 27, 2014; Accepted September 27, 2014; Published September 30, 2014

*Corresponding author Yong-Gu Cho, ygcho@cbnu.ac.kr, Tel: +82-43-261-2514, Fax: +82-43-273-2242

${ }^{\S}$ These authors contributed equally to this paper 
genes: one SSSI, three SSSII, two SSSIII, and two SSSIV isoforms, and most SSS isoforms are expressed in endosperm (Dian et al. 2005; Jiang et al. 2004). The soluble starch synthase isoforms generate chains in amylopectin and are either soluble in plastid stroma, or partially soluble and partially associated with granule. Genetic and biochemical data indicate that each SSS isoform has different properties and distinct roles in amylopectin synthesis. Analysis of the distribution of chain lengths of amylopectin in mutant and transgenic plants lacking specific isoforms has led to the idea that SSSI, SSSII and SSSIII classes preferentially elongate short, medium, and long chains, respectively (James et al. 2003). SSSI and SSSIIIA are the major isoforms of soluble starch synthase in endosperm. SSSI activity is also higher than that of SSSIIIA, accounting for about $70 \%$ of the total SSS activity (Fujita et al. 2007). Biochemical evidence suggests that short $\mathrm{A}$ and $\mathrm{B}_{1}$ chains are extended by SSSI up to a critical length, that is, those with a degree of polymerization of 10 glucosyl units or less (Commuri and Keeling 2001). SSSI is then tightly bound to longer amylopectin chains, whereupon it becomes entrapped within longer glucans as a relatively inactive protein in starch granules. Thus, further glucan chain extension for amylopectin synthesis is most likely catalyzed by SSSII and SSSIII isoforms (Jeon et al. 2010).

SSSI may play important role in starch biosynthesis in rice because of only one isoform unlike other SSS types having more than two isoforms in rice (Fujita et al. 2006; Hirose and Terao 2004). Moreover, more than $85 \%$ of SSSI in maize endosperm is associated with starch granules (Mu-Forster et al. 1996). Guan and Keeling (1998) analyzed the chain-length distribution of poly-glucans synthesized by different combinations of maize SSSI and SBE isoforms in E. coli to understand the function of SSSI and reported that SSSI synthesized short chain (DP 6-15). In japonica rice, the SSSI mutation had no effect on the size or shape of seeds and starch granules, or on the crystallinity of endosperm starch (Fujita et al. 2011). However, the changes in amylopectin chain-length distribution were studied in four allelic mutants, in which Tos 17 was inserted into the SSSI gene in different position. SSSI activities of four mutants were different that were positively correlated with the degree of changes in amylopectin chain-length distribution (Fujita et al. 2006).

Recent analyses of protein-protein interactions have strongly suggested that SSSI, SSSIIa, and SBEIIb interact during starch biosynthesis in maize (Liu et al. 2009; Liu et al. 2012). SSS and SBE isozymes in developing rice endosperm likely cooperate with each other during starch biosynthesis. Analysis of double mutant lines with mutations in genes encoding SSS and SBE isozymes is one strategy to further analyze the interactions among these enzymes and their functions. There is a close interaction among SSSI, SBEI and SBEIIb during amylopectin biosynthesis in rice endosperm (Abe et al. 2014). Analysis of the chain-length distribution in amylopectin of the double mutant lines showed that SSSI and SBEI or SBEIIb primarily function independently, and branching by SBEIIb is followed by SSSI chain elongation.

This study was carried out to evaluate the effect of SSSI downregulation to the amylose content and characterize the resulting starch granules in transgenic japonica rice.

\section{MATERIALS AND METHODS}

\section{Vector construction and plant transformation}

Rice cDNA was synthesized and used to amplify OSSSSI (AK109458) gene. A sense SSSI fragment was amplified from rice cDNA using the primer pair 5'-GGGGTACCTT-

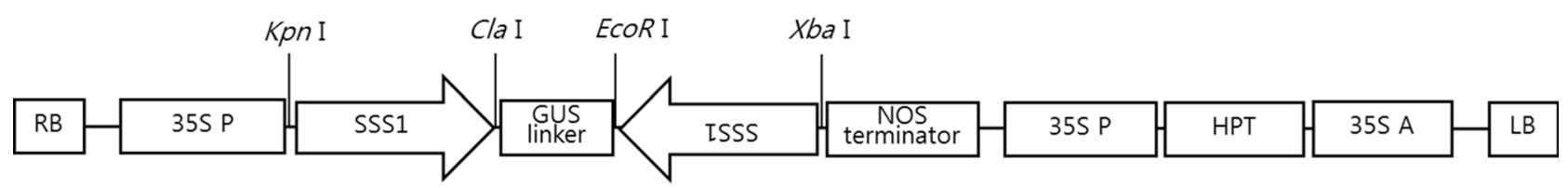

Fig. 1. T-DNA region of $p C A M S-R i$. RB: right border, LB: left border, SSSI: fragments targeting SSSI gene (533 bp of the complete CDS), GUS: $\beta$-glucuronidase gene, NOS: nopaline synthetase terminator, 35S P: cauliflower mosaic virus (CaMV) 35S promoter, HPT: Hygromycin phosphotransferase, 35S A: CaMV 35S poly A. 
GGAAGATTGGACTATC-3' and 5'- CCATCGATTTCGAAGATCTGTTCATACTG-3', while an antisense SSSI fragment was amplified using the primers 5'-GCTCTAGAGCTTGGAAGATTGGACTATC-3' and 5'-GGAATTCCTTCGAAGATCTGTTCATACTG -3'. GUS gene (AJ298139) was used as a spacer for dsRNA formation and was inserted between the sense SSSI fragment and the antisense SSSI fragment. The DNA fragment was ligated into a $p C A M B I A 1300$ vector. The recombinant vector carrying RNAi-SSSI was constructed under the control of CaMV 35S promoter and NOS terminator, as shown in Fig. 1. The RNAi-SSSI construct was transformed into $A$. tumefaciens LBA4404 and then introduced into rice using Agrobacterium-mediated method (Lee et al. 2011) with minor modifications.

\section{Cultivation and evaluation of transgenic rice}

A rice variety Gopum was used as a material to generate transgenic rice. Regenerated plants on root formation medium were transplanted in soil (50\% compost and 50\% soil) and covered with plastic bags until plants grew well under greenhouse condition for acclimatization. Young leaf samples for confirming transgenic plants were collected for genomic DNA analysis. RNAi-SSSI $\mathrm{T}_{1}$ seeds were harvested and transplanted in the experimental farm of Chungbuk National University. Rice cultivation was carried out by applying N- $\mathrm{P}_{2} \mathrm{O}_{5}-\mathrm{K}_{2} \mathrm{O}$ fertilizers at the rate of $90-45-47 \mathrm{~kg}$ $\mathrm{ha}^{-1}$, controlling water irrigation, and prevention and control of pests and diseases.

\section{DNA extraction and polymerase chain reaction (PCR)}

Genomic DNA was extracted according to the procedure in Cho et al. (2011) and Abdula et al. (2013) with minor modifications. The relative purity and concentration of extracted DNA were estimated using a NanoDrop-1000 spectrophotometer (NanoDrop Technologies). PCR analysis was performed using HPT-Fw: 5'-ATTTGTGTACGCCCGACAGT-3' and HPT-Rv: 5'- GGGATTCCCAATACGAGGTC-3' primers to check the introgression of Hygromycin phosphotransferase gene (HPT), and PIX-Rv: 5'-AGAGCATTACGCTGCGATG-3' and NOS-Rv: 5'-AAGACCGGCAACAGGATTC-3' primers to check the introgression of the full-length cDNA.

\section{Gene expression analysis}

Total RNAs were isolated from rice grains using the RNeasy mini kit (Qiagen) according to the manufacturer's instruction with some modifications. Total RNAs were cleaned using DNaseI kit (Invitrogen), and the first-strand cDNA synthesis was performed by reverse transcription of mRNA using Oligo $(\mathrm{dT})_{20}$ primer and SuperScript ${ }^{\mathrm{TM}}$ III Reverse Transcriptase (Invitrogen). The specific sequences of the primer pairs used in a semi-quantitative reverse transcription PCR (RT-PCR) are SSSI-Fw: 5'-GGAACCCATCCACAGACAAG-3', and SSSI-Rv: 5'-GAAATTCGCTGCTTCCTTC A-3'. Actin primer was used as internal control for normalization of quantitative RT-PCR reaction.

\section{Apparent amylose content determination}

The apparent amylose content in unpolished $\mathrm{T}_{2}$ rice was determined as described in Stawski (2008) with some modifications. Ten $\mathrm{mg}$ of fine ground unpolished rice powder was dispersed in $100 \mu 1$ of $100 \%$ ethanol, and then $900 \mu 1$ of $1 \mathrm{~N} \mathrm{NaOH}$ was added with swirling to improve dispersion. The contents were heated to boiling at $100^{\circ} \mathrm{C}$ for 30 min until starch completely gelatinized. The test tube was cooled, mixed on a vortex mixer, and filled to the $10 \mathrm{ml}$ mark with distilled water. To make a duplicate, $500 \mu 1$ of sample was taken into a new $20 \mathrm{ml}$ test tube containing $5 \mathrm{ml}$ of distilled water. The sample was neutralized with $100 \mu \mathrm{l}$ of $1 \mathrm{M}$ acetic acid, then $200 \mu \mathrm{l}$ of fresh iodine-potassium iodide solution (120 mM KI, $8 \mathrm{mM} \mathrm{I}_{2}$ ) and $4.2 \mathrm{ml}$ of distilled water was added. The tubes were mixed on a vortex mixer, and then incubated at $30^{\circ} \mathrm{C}$ for $30 \mathrm{~min}$ in the dark, and the absorbance of duplicated subsamples was measured at $620 \mathrm{~nm}$ using a spectrophotometer. The standard curve was set up using $1 \mathrm{mg} \mathrm{ml}^{-1}$ standard amylose and $1 \mathrm{mg} \mathrm{ml}^{-1}$ standard amylopectin solution from potato (Sun et al. 2011).

\section{SBE activity assay}

Enzyme activity of starch branching enzyme namely, SBEI, SBEIII, and SBEIV together in rice grains was 
assayed as described in Yamanouchi and Nakamura (1992) with some modifications. Fifteen frozen rice endosperms were homogenized in $10 \mathrm{ml}$ of cold extraction buffer (50 mM HEPES-NaOH pH 7.4, 4 mM MgCl 2,50 mM 2-mercaptoethanol, $12.5 \%$ glycerol) on ice, and were centrifuged at $15,000 \mathrm{rpm}$ at $2^{\circ} \mathrm{C}$ for $20 \mathrm{~min}$, and the supernatants were then filtered through a filter paper $(0.45 \mu \mathrm{m}$, Whatman). The filtrates were used for enzyme preparations.

Starch branching enzyme was assayed by monitoring stimulation of a-glucan synthesis from glucose-1-phosphate by rabbit muscle phosphorylase (Hawker et al. 1974; Nakamura et al. 1989). One hundred microlitter of enzyme preparation was added into $100 \mu \mathrm{l}$ of cold reaction buffer (50 mM HEPES-NaOH pH 7.0, 50 mM glucose-1-phosphate, $2.5 \mathrm{mM}$ AMP, 1.2 units of phosphorylase a from rabbit muscle), and was incubated at $30^{\circ} \mathrm{C}$ for $30 \mathrm{~min}$. The reaction was terminated by adding $50 \mu \mathrm{l}$ of $1 \mathrm{M} \mathrm{HCl}$, and mixed with $500 \mu \mathrm{l}$ of dimethylsulfoxide. $700 \mu \mathrm{l}$ of fresh iodine-potassium iodide solution (120 mM KI, $8 \mathrm{mM} \mathrm{I}_{2}$ ) was added into the solution, and then incubated at $30^{\circ} \mathrm{C}$ for $30 \mathrm{~min}$ in dark place. The SBE activity was determined by measuring the absorbance at $540 \mathrm{~nm}$ in a UV spectrophotometer (Shimadzu). Three replications were carried out in this experiment.

\section{GBSSI and SSSI extraction}

GBSSI and SSSI enzyme extractions were conducted as described in Umemota and Terashima (2002) with some modifications. Fifteen frozen rice endosperms were homogenized manually in $2 \mathrm{ml}$ of cold extraction buffer (100 mM Tris pH 7.2, 2 mM EDTA, 2 mM DTT, 10\% ethanediol). The homogenate was then centrifuged at $15,000 \mathrm{rpm}$ at $2{ }^{\circ} \mathrm{C}$ for $20 \mathrm{~min}$. The supernatant was collected and filtered through a membrane filter $(0.45 \mu \mathrm{m}$, Whatman $)$, and the filtrate was used for the assay of SSSI. The pellet was washed three times by suspension and centrifugation using extraction buffer. The washed pellet was resuspended in 3 $\mathrm{ml}$ extraction buffer and used for GBSSI assay.

\section{SSSI activity assay}

The enzyme activity of SSSI was assayed as described in Nishi et al. (2001) with some modifications. $0.15 \mathrm{ml}$ of SSS preparation was added into $0.15 \mathrm{ml}$ of buffer A $(0.5 \mathrm{M}$ citrate-Na pH 7.5, 50 mM Bicine- $\mathrm{NaOH}$ pH 7.5, $1.7 \mathrm{mM}$
ADP-glucose, $0.7 \mathrm{mg}$ oyster glycogen TypeII, $16.7 \mathrm{mM}$ DTT), and incubated at $30^{\circ} \mathrm{C}$ for $20 \mathrm{~min}$. The enzyme was inactivated by placing the mixture in a boiling-water bath for $30 \mathrm{~s}$, and incubated on ice for $10 \mathrm{~min}$. The mixture was supplemented with $0.1 \mathrm{ml}$ of Buffer B (50 mM HEPES$\mathrm{NaOH}$ pH 7.4, $10 \mathrm{mM}$ phosphocreatine, $200 \mathrm{mM} \mathrm{KCl}, 10$ $\mathrm{mM} \mathrm{MgCl}, 10 \mu \mathrm{l}$ of $5 \mathrm{mg} \mathrm{ml}^{-1}$ creatine phosphokinase (5 units $\mathrm{ul}^{-1}$, TypeI), and then incubated at $30^{\circ} \mathrm{C}$ for $30 \mathrm{~min}$. The ADP produced by the soluble starch synthase reaction was converted to ATP, and the resulting solution was heated in a boiling water bath for $30 \mathrm{~s}$, and incubated on ice for $10 \mathrm{~min}$, and then subjected to centrifugation at 15,000 rpm for $15 \mathrm{~min}$ at $2^{\circ} \mathrm{C}$. The supernatant $(0.3 \mathrm{ml})$ was mixed with $0.3 \mathrm{ml}$ of buffer $\mathrm{C}$ (125 mM HEPES-NaOH pH 7.4, 10 $\mathrm{mM}$ glucose, $20 \mathrm{mM} \mathrm{MgCl} 2,150 \mu \mathrm{g}$ NADP). The SSS activity was measured as the increase in absorbance of 340 $\mathrm{nm}$ after the addition of $1.1 \mu \mathrm{l}$ of hexokinase (1.4 units $\mu \mathrm{l}^{-1}$, Roche) and $1.5 \mu$ l of glucose-6-phosphatedehydrogenase $\left(0.35\right.$ units $\mu l^{-1}$, Type XV) at $25^{\circ} \mathrm{C}$ for $30 \mathrm{~min}$. Three replications were carried out in this experiment.

\section{GBSSI activity assay}

The activity of GBSSI was assayed as described in Nakamura et al. (1989) with some modifications. $0.15 \mathrm{ml}$ of GBSSI enzyme preparation was added into $0.15 \mathrm{ml}$ of solution A (50 mM HEPES-NaOH pH 7.4, 1.6 mM ADP glucose, $0.7 \mathrm{mg}$ amylopectin, $15 \mathrm{mM}$ DTT), and incubated at $30^{\circ} \mathrm{C}$ for $1 \mathrm{hr}$. The enzyme was inactivated by placing the mixture in a boiling-water bath for $30 \mathrm{~s}$, and incubated on ice for $10 \mathrm{~min}$. The mixture was then added with $0.1 \mathrm{ml}$ of solution B (50 mM HEPES-NaOH pH 7.4, 4 mM PEP, 200 $\mathrm{mM} \mathrm{KCl}, 10 \mathrm{mM} \mathrm{MgCl}_{2}, 1.5$ units of pyruvate kinase) and incubated at $30^{\circ} \mathrm{C}$ for $30 \mathrm{~min}$. The ADP produced by the starch synthase reaction was converted to ATP and the resulting solution was heated in a boiling water bath for 30 $\mathrm{s}$, and incubated on ice for $10 \mathrm{~min}$, and then subjected to centrifugation at $15,000 \mathrm{rpm}$ for $15 \mathrm{~min}$ at $2^{\circ} \mathrm{C}$. The supernatant $(0.3 \mathrm{ml})$ was mixed with $0.3 \mathrm{ml}$ of solution $\mathrm{C}$ (50 mM HEPES-NaOH pH 7.4, $10 \mathrm{mM}$ glucose, $20 \mathrm{mM}$ $\mathrm{MgCl}_{2}, 2$ mM NADP). The GBSSI activity was measured as the increase in absorbance of $340 \mathrm{~nm}$ after the addition of $1 \mu \mathrm{l}$ each of hexokinase (1.4 units $\left.\mathrm{ul}^{-1}\right)$ and glucose-6phosphate dehydrogenase $\left(0.35\right.$ units $\left.^{-1} l^{-1}\right)$ at $25^{\circ} \mathrm{C}$ for 30 
$\min$. Three replications were carried out in this experiment.

\section{Eating quality traits evaluation}

For physicochemical analyses, rice grains were dehulled and milled to $91 \%$ yield. The analyses were performed as described in Lestari et al. (2009) with some modifications. The amylose content of milled rice was measured using the relative absorbance of starch-iodine color in a digested solution of 100-mesh rice flour as described in Perez and Juliano (1978). The amylose content measured from iodine-binding capacity was named as apparent amylose content. Thus, actual amylose content was derived from apparent content by subtracting the contribution of the long chains of amylopectin (Takeda et al. 1987). The viscosity of the cooked rice grain was analyzed using the Rapid Visco Analyzer (RVA) to obtain RVA profiles (Model No. RVA-4; Newport Scientific), according to Standard Method AACC61-02 released by the American Association of Cereal Chemists. Briefly, approximately $3 \mathrm{~g}$ of rice flour was mixed with $25 \mathrm{ml}$ water. The sequential temperature curve for a $12.5 \mathrm{~min}$ test was as follows: (1) incubation at 50 ${ }^{\circ} \mathrm{C}$ for $1 \mathrm{~min}$; (2) increase in temperature to $95^{\circ} \mathrm{C}$ and holding for $2.5 \mathrm{~min}$; (3) cooling to $50^{\circ} \mathrm{C}$ and holding at 50 ${ }^{\circ} \mathrm{C}$ until the end of the cycle. RVA profiles were characterized by five parameters: peak viscosity (PKV), hot paste viscosity (HPV), cool paste viscosity (CPV), breakdown viscosity $(\mathrm{BDV}=\mathrm{PKV}-\mathrm{HPV})$, and setback viscosity $(\mathrm{SBV}=\mathrm{CPV}-\mathrm{PKV})$. All the viscosity parameters were expressed in rapid visco units.

\section{RESULTS}

\section{RNAi vector construction and generation of transgenic plants}

To down-regulate SSSI gene expression, $p C A M B I A 1300$ vector with Hygromycin phosphotransferase gene (HPT) regulated by $35 \mathrm{~S}$ promoter was used to enable hygromycinbased plant selection. The part of open reading frame of SSSI gene was selected to form a hairpin loop and inserted into multiple cloning sites between $K p n \mathrm{I}$ and $X b a \mathrm{I}$ of the modified $p C A M B I A 1300$ vector carrying $35 \mathrm{~S}$ promoter and nopaline synthase (NOS) terminator. The final expression vector was named as $p C A M S$-Ri (Fig. 1).

Transgenic rice lines were generated using Agrobacteriummediated transformation method described in Lee et al. (2011) with some modifications. To select the homozygous lines, germination test in 5\% hygromycin solution was conducted using $T_{1}$ seeds. Seeds that grew in hygromycin solution were advanced to the next generation (data not shown). Genomic PCR was done among the generated transgenic rice plants using $P I X-\mathrm{Rv}$ and $N O S$-Rv primers.

(A)

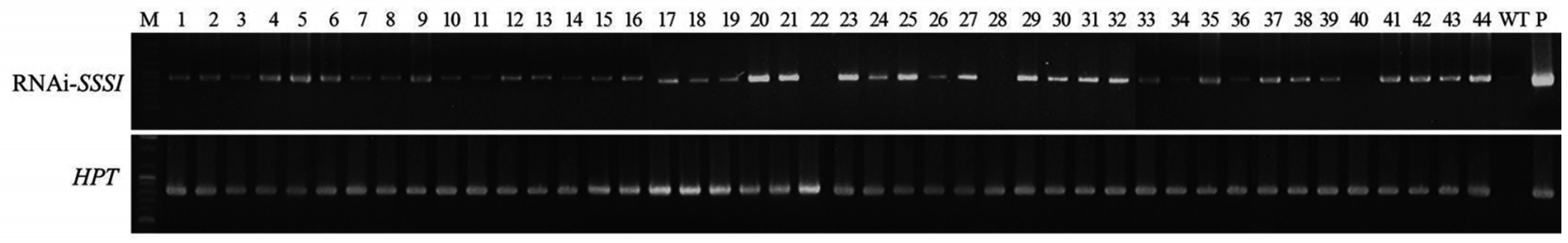

(B)

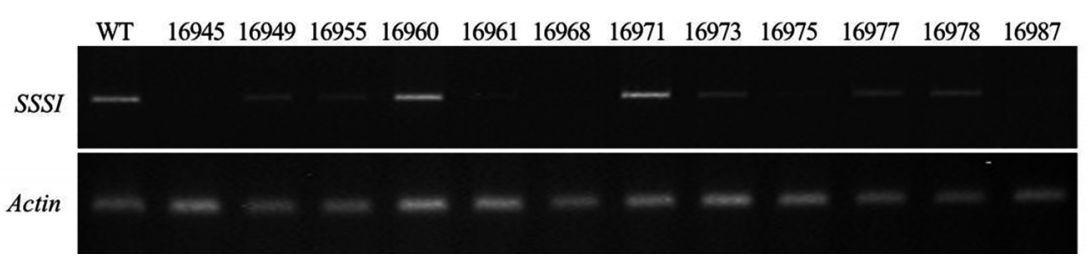

Fig. 2. Genomic and expression analysis of transgenic plants and wild type. (A) PCR confirmation of transgenes in transgenic plants using Gus-Fw, Nos-Rv and HPT primers loaded on $1 \%$ agarose gel. (B) Expression of SSSI genes in regenerated transgenic rice plants using young leaf. Upper panel shows expression level of introduced SSSI and lower panel shows internal actin used for loading adjustment. WT, wild type; P, plasmid DNA. 
As shown in Fig. 2A, 768 bp of the target gene was amplified from the positive transgenic plants while the wild type Gopum showed no amplification. Moreover, HPT marker gene was also amplified in entries with RNAi-SSSI gene. We chose 12 transgenic homozygous lines according to the segregation ratio in hygromycin screening (data not shown). In $\mathrm{T}_{1}$ generation of RNAi-SSSI transgenic plants, a semi-quantitative RT-PCR was carried out to measure the expression level of SSSI gene. Fig. 2B shows that the expression level of SSSI gene in ten transgenic plants was much lower than in wild type (WT) implying that low expression of SSSI gene was obtained successfully by RNAi technology. However, degree of expression level showed variable pattern among the transgenic lines.

\section{Amylose content}

$\mathrm{T}_{2}$ seeds from RNAi-SSSI transgenic rice plants were used to quantify the amylose content of each plant. The amylose contents of the transgenic rice grains were measured and compared with the wild type Gopum, with $18 \%$ amylose content, and the low amylose content $(4.3 \%)$ control Dongjinchal, as controls. Amylose content analysis revealed a wide range of values as shown in Fig. 3. RNAiSSSI transgenic lines showed various distributions of amylose contents that ranged from 11 to $17 \%$. Fifty-one out of 70 transgenic lines showed amylose contents between $13 \%$ to $16 \%$, the ideal levels we thought useful for development of high eating quality varieties.

Rice was categorized into four groups depending on amylose contents, waxy (0-5\%), low amylose (7-20\%), middle amylose (21-25\%) and high amylose $(>25 \%)$ (Lestari et al. 2009). So, the amylose contents of RNAiSSSI transgenic lines corresponded particularly to the case of low-amylose rice.

mRNA expression and iodine staining of rice grains in $T_{2}$ generation

A total of five lines having weak mRNA expression and low amylose contents were selected for this experiment. These lines were used in mRNA expression analysis of the targeted gene in the grains at ripening stage, and for iodine analysis in the seeds. In $\mathrm{T}_{2}$ generation of RNAi-SSSI transgenic plants, grain samples were collected at 22 days after flowering (DAF). A semi-quantitative RT-PCR was carried out to measure the expression level of SSSI gene after rice flowering. Fig. 4 showed that the mRNA expression of SSSI gene at 22 DAF was significantly lower compared with the wild type. Moreover, amylose contents in rice seeds of transgenic lines were lower than in Gopum but showed different pattern in each transgenic line which

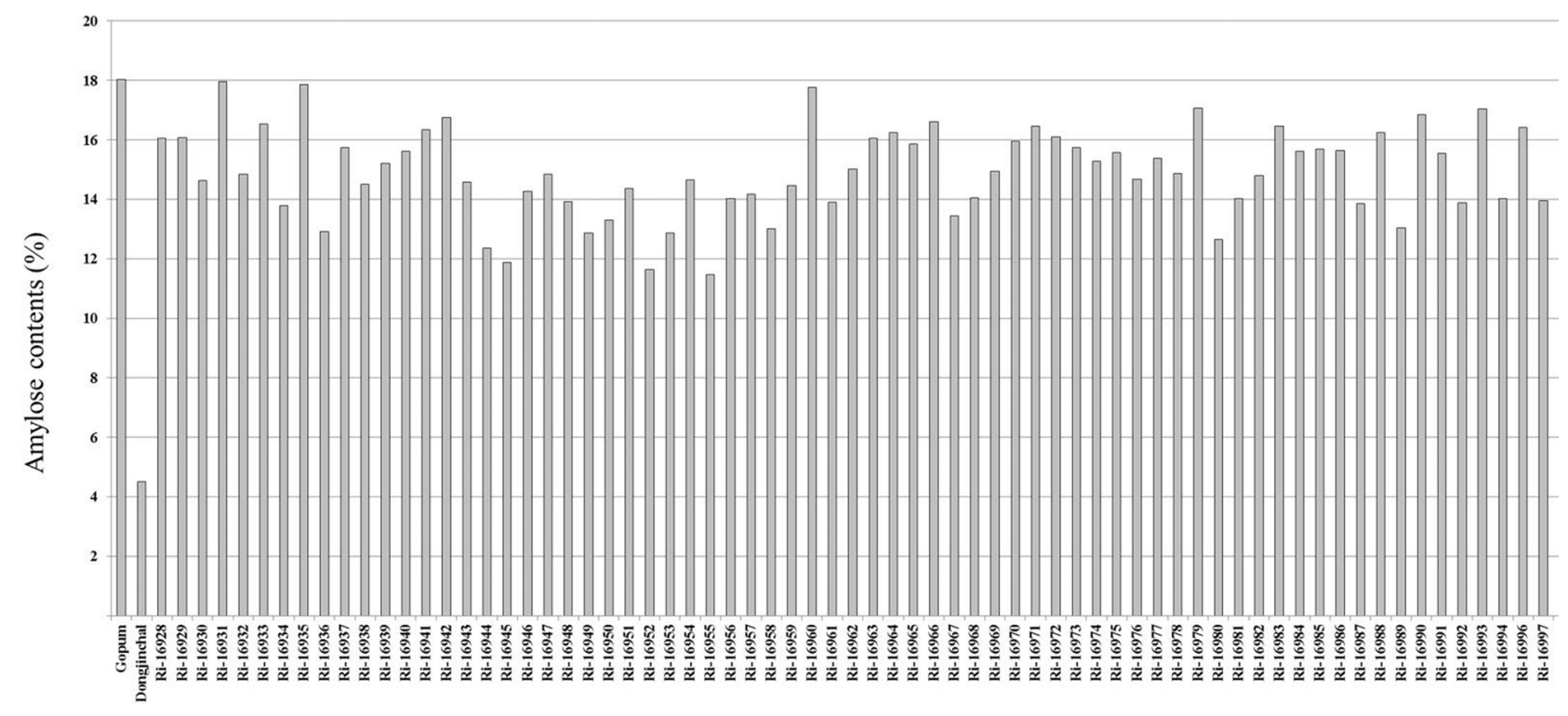

Fig. 3. Amylose contents in wild type and RNAi-SSSI transgenic rice grains. 
range from 11.6 to $15.6 \%$.

To visually determine the change in amylose content of the transgenic plants, $\mathrm{T}_{2}$ transgenic seeds of RNAi-SSSI were subjected to Lugol's solution or iodine staining (Pedersen et al. 2004). Iodine reacts in the presence of starch, which turned into dark purple or even black. The wild type Gopum with $18 \%$ amylose content showed a dark blue color after staining with iodine solution (Fig. 4). RNAi-SSSI seeds showed various reactions from normal blue to light blue color, indicating that the lower levels of amylose contents were generated by RNAi-SSSI transgenic plants. Interestingly, the rice grains developed from the
RNAi-SSSI transgenic plants showed clear non-glutinous endosperm grain type with lower amylose levels, which is the ideal grain type.

\section{Enzyme activities related to amylose biosynthesis from transgenic plants}

There are three major enzymes involved in amylose synthesis namely, starch branching enzyme (SBE), granule bound starch synthase (GBSS), and soluble starch synthase (SSS). The activity of each of these enzymes was measured in wild type and transgenic plants which had lowest amylose content at 22 DAF (Fig. 5). Gopum and RNAi-SSSI

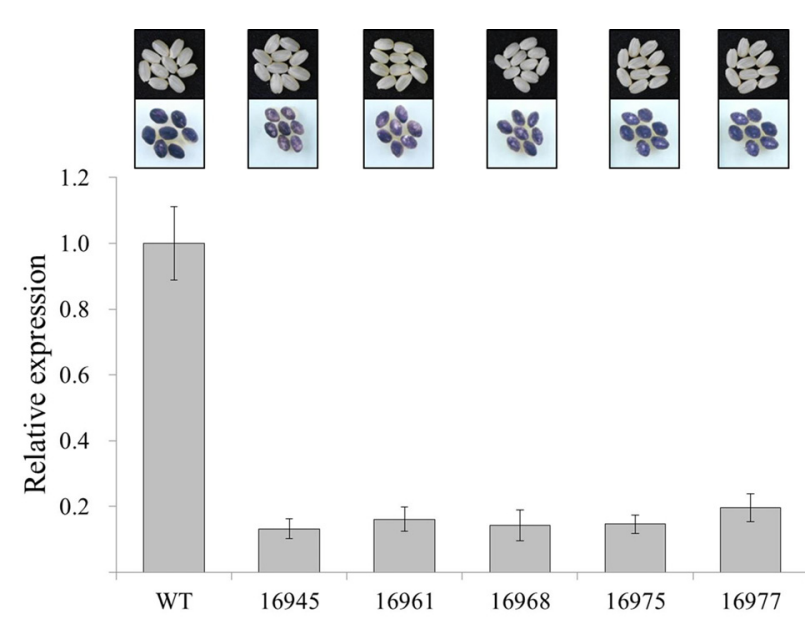

Fig. 4. Iodine staining and mRNA expression of wild type and RNAi-SSSI transgenic rice seeds. Iodine analysis was conducted using dried mature grain and grain samples were collected at 22 days after flowering (DAF) to mRNA expression analysis.
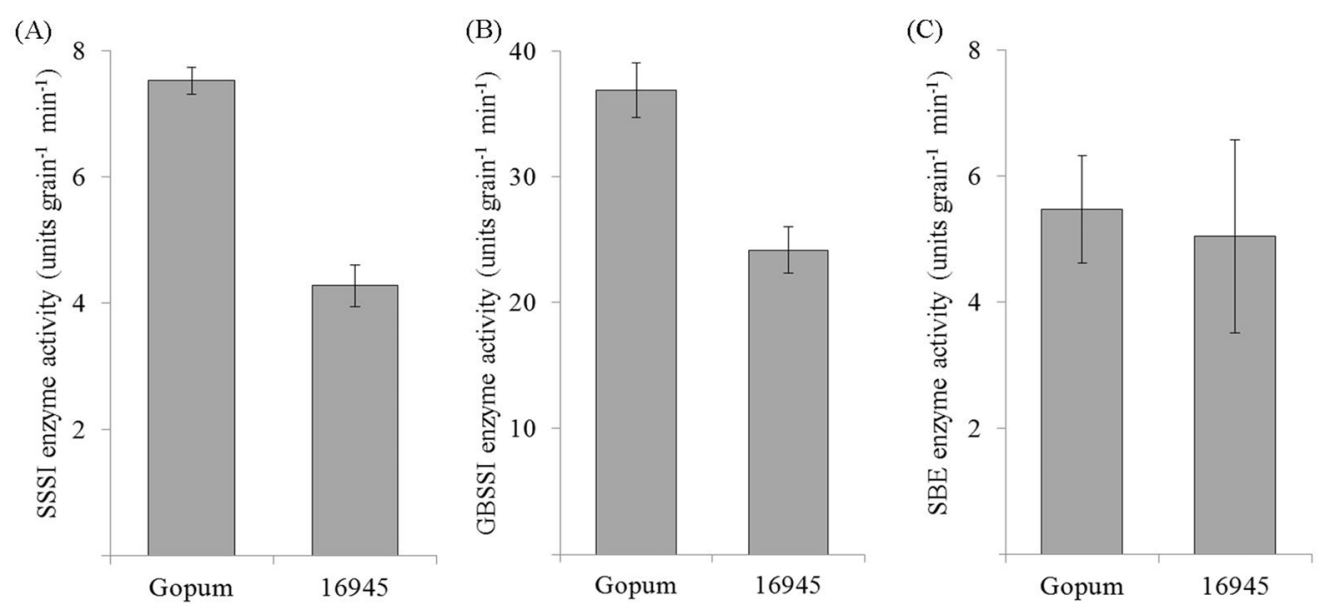

Fig. 5. Enzyme activities of SSSI, GBSSI and SBE related to amylose biosynthesis in RNAi-SSSI transgenic rice seeds. Grain samples were collected at 22 days after flowering to mRNA expression analysis. 
transgenic plants showed different enzyme activities. SSSI activity of RNAi-SSSI transgenic plant was much lower than in wild type (Fig. 5A). SSSI enzyme activity was about twice in Gopum than in transgenic seeds. Similarly, GBSSI enzyme activity of transgenic rice seeds was lower than that of wild type (Fig. 5B). However, SBE activities in transgenic plants had no significant difference with wild type (Fig. 5C). The genes regulating starch synthesis including starch branching enzyme genes and soluble starch synthase genes had minor effects on amylose content, gel consistency, and palatability (Hsu et al. 2014). When RNAi was applied in SSSI, the SBE enzyme activity had the same level with wild type, while GBSSI activity was low. Henceforth, the decreasing SSSI activity by RNAi was reflected to the decrease of GBSSI activity. In this result, the lower GBSSI activity enhances the biosynthesis of amylopectin in the grain filling of transgenic RNAi-SSSI plants.

\section{Eating quality traits evaluation}

The physicochemical properties of cooked rice grains revealed by RVA profiles are commonly recognized as
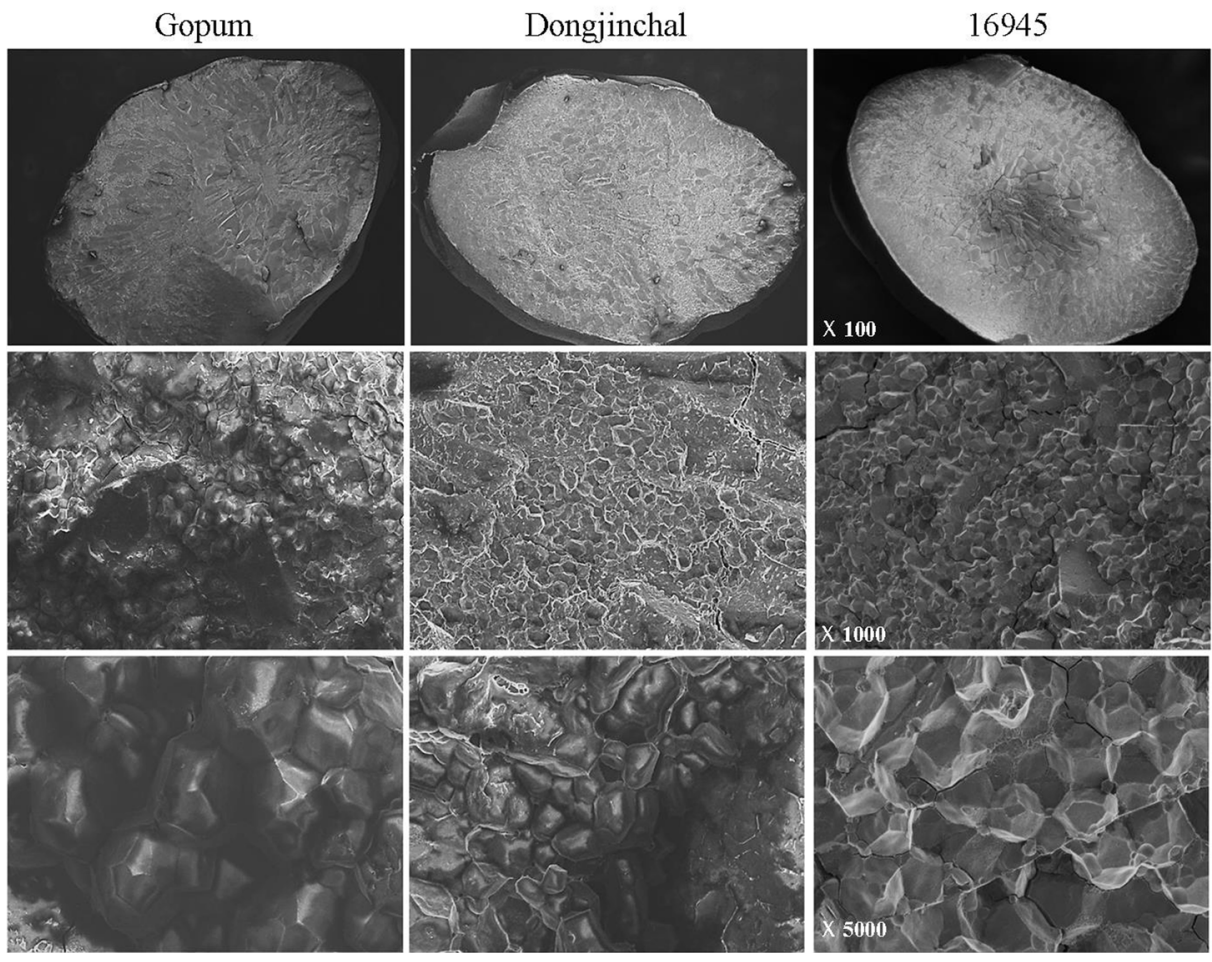

Fig. 6. The scanning electron microscope (SEM) analysis of Gopum (wild type), Dongjinchal (glutinous rice), and transgenic mature grain.

Table 1. Eating quality parameters of RNAi-SSSI transgenic lines and the wild type variety, Gopum.

\begin{tabular}{ccccccccc}
\hline \hline Variety & AAC (\%) & PC (\%) & PV & HPV & CPV & BDV & SBV & CTV \\
\hline Gopum & 18.02 & 7.6 & 268.83 & 161.90 & 269.56 & 106.93 & 0.72 & 107.66 \\
16945 & 12.36 & 8.8 & 289.61 & 151.40 & 267.07 & 125.42 & -6.47 & 118.96 \\
16961 & 12.92 & 8.3 & 301.61 & 139.20 & 245.78 & 150.41 & -43.83 & 106.58 \\
16968 & 13.04 & 10.2 & 255.83 & 148.45 & 254.80 & 107.38 & -1.03 & 106.35 \\
16975 & 16.09 & 7.5 & 303.78 & 136.95 & 259.07 & 166.83 & -44.71 & 122.12 \\
\hline
\end{tabular}

AAC, apparent amylose content; PC, protein contents; PV, peak viscosity; HPV, hot paste viscosity; CPV, cool paste viscosity; BDV, breakdown viscosity; SBV, setback viscosity; CTV, consistency viscosity 
several characteristics including peak viscosity (PV), hot paste viscosity (HPV), breakdown viscosity (BDV), cool paste viscosity (CPV), setback viscosity (SBV), and total setback or derived characteristics, such as consistency viscosity (CSV), relative breakdown, setback ratio, and consistency ratio (Bergman et al. 2004). Table 1 showed the apparent amylose content (AAC) of Gopum that is significantly higher than transgenic plants. All parameters related to cooking and eating quality vary in transgenic lines. HPV and CPV in transgenic lines were lower than in wild type. Breakdown viscosity was higher value in the transgenic lines, but SBV in transgenic lines was much lower than in wild type. Hsu et al. (2014) reported that HPV and CPV showed a positive correlation, while BDV and SBV were negatively correlated. RVA profile result indicated that the down-regulation of SSSI gene affects the physicochemical properties of rice grains suggesting that SSSI gene modification may improve the eating quality in rice.

\section{Physical structure of rice grain}

Starch granule morphology can influence the physicochemical characteristics of starch, and granule shape or sizes are a contributing factor in starch functional properties. In this study, the surface structure of starch granules was analyzed using a scanning electron microscope (SEM) to reveal the changes in structure from the wild type to the transgenic rice grains. As shown in Fig. 6, the starch of wild type have a large granule structures accompanied with small ones on its vicinity. On the other hand, Dongjinchal, a glutinous rice, showed very fine structures of starch granules covering the entire section. Interestingly, SEM analysis supports the findings of iodine staining and amylose content analysis. The samples from RNAi-SSSI showed intermediate size relative to the two controls used, showing smooth curves with most structures having a uniform shape unlike the controls with sharp edges and various irregular shapes and sizes.

\section{DISCUSSION}

In this study, we used RNAi technology to target SSSI gene that plays a critical role on improving the palatability of rice contributed by amylose content. We studied the transgenic plants for expression of the down-regulated SSSI gene, activity of enzymes related to starch biosynthesis, amylose content, and the starch granule structures.

Expression of SSSI gene could be manipulated using the RNAi technology. Indeed, the expression level of SSSI gene in transgenic lines was lower than in Gopum (Fig. 2B). However, the degree of expression level showed variable pattern among the transgenic lines. The chromosomal position of T-DNA has been reported to be important for the expression level of transgene, and that reproducible insertion into the same chromosome position is capable of generating the same expression level (Day et al. 2000). Therefore, position of the integrated gene may effect to a distinct level of expression for transgenic lines. Otani et al. (2007) reported that amylose-free sweet potato was developed by mRNA activity of GBSSI gene. Similar result was reported by the work using RNAi in phytoenedesaturase $(P D S)$ gene which reduced mRNA expression (Miki and Shimamoto 2004). In our experiment, RNAi transgenic rice showed inhibited expression of SSSI gene. This validates our hypothesis that SSSI gene expression in rice grain can be controlled using RNAi technology.

The RNAi-SSSI was shown to produce transgenic rice with $11 \%$ to $17 \%$ amylose contents in the $\mathrm{T}_{1}$ seeds. The transgenic grains, however, contained highly variable amylose content. We proceeded by selecting transgenic lines containing low amylose contents. Interestingly, diverse responses of SSSI, GBSSI and SBE in the developing grains of RNAi transgenic plants were observed (Fig. 5). Gopum and RNAi-SSSI transgenic plants showed different enzyme activities in rice grains at $22 \mathrm{DAF}$. This could be due to the down-expression vectors effecting low expression of SSSI which subsequently affected other various enzymes (SSS, SBE and SDBE) in amylopectin synthesis. It is known that amylose is synthesized by AGPase and GBSS, and amylopectin is synthesized by concerted reactions catalyzed by AGPase, SSS, SBE and SDBE (Myers et al. 2000; Nishi et al. 2001). SBE is the only enzyme that can introduce a -1,6-glucosidic linkages into a-polyglucans, and therefore, it plays a crucial role in the biosynthesis of amylopectin. RNAi-SSSI transgenic lines may have affected the activities 
of SBE and SDBE indirectly by reducing the enzymatic activity of SSSI. The interaction of SSS, SBE and SDBE isoforms associated with amylopectin synthesis enzymes needs to be further investigated.

Rice was categorized into four groups depending on amylose contents; waxy (0-5\%), low amylose (7-20\%), middle amylose (21-25\%) and high amylose $(>25 \%)$ (Lestari et al. 2009). The amylose contents of RNAi-SSSI transgenic lines corresponded particularly to the case of low-amylose rice. Although the wild type Gopum is classified as low amylose rice (18.0\%), but the amylose contents in the transgenic lines were much lower ( $11.6 \%$ to $15.6 \%$ ). Amylose content is a major determinant of rice cooking and eating characteristics (Asghar et al. 2012). The physicochemical properties of cooked rice grains were investigated by RVA profiles to reveal the pasting properties of starch in the cooked rice. In this study, physicochemical properties in the transgenic lines were different from the wild type. This result implies that regulation of SSSI gene function affected the physicochemical properties of rice grains. Many studies also have reported that the control of starch synthesis-related genes, such as SSS, SBE and PUL had minor effects on physicochemical properties of rice grains (Pandey et al. 2012; Sun et al. 2011; Tian et al. 2009).

Scanning electron microscope (SEM) and viscosity analysis were carried out to reveal the starch granule structures of wild type and transgenic lines. By comparison, the shapes of granules in wild type were irregular, while the starch granules of RNAi transgenic lines exhibited a uniform size with smooth curves. In the study conducted by Wei et al. (2010), they used antisense method in decreasing starch branching enzyme (SBE) activity which resulted in high amylose content transgenic rice. And under SEM analysis, their transgenic rice has large starch granules relative to the wild type. The angles and edges of granules changed to round and elongated shape. Based on the results, the size of starch granule was thought to be associated with the amylose content.

In summary, the RNAi-SSSI transgenic lines produced low amylose contents that fell between glutinous and nonglutinous rice, accompanied with changes in physicochemical properties of rice grains. This study showed that downregulation of endogenous SSSI through RNAi is an invaluable technique that could aid in developing rice variety with improved eating quality.

\section{ACKNOWLEDGMENTS}

This work was supported by a grant from the NextGeneration BioGreen 21 Program (Plant Molecular Breeding Center No. PJ008129), Rural Development Administration, and by a research grant of the iPET, Ministry for Food, Agriculture, Forestry and Fisheries, Republic of Korea.

\section{REFERENCES}

Abdula SE, Lee HJ, Jee MG, Jung YJ, Kang KK, Nou IS, Lee SB, Yang WH, Cho YG. 2013. Development and identification of transgenic rice lines with abiotic stress tolerance by using a Full-length OvereXpressor gene Hunting System. Plant Breed. Biotech. 1: 33-48.

Abe N, Asai H, Yago H, Oitome NF, Itoh R, et al. 2014. Relationships between starch synthase I and branching enzyme isozymes determined using double mutant rice lines. BMC Plant Biol. 14: 80.

Asghar S, Anjum FM, Amir RM, Khan MA. 2012. Cooking and eating characteristics or rice (Oryza sativa L.). Pak. J. Food Sci. 22:128-132.

Bergman CJ, Bhattacharya KR, Ohtsubo K. 2004. Rice endusequality analysis. RICE: chemistry and technology. American Association of Cereal Chemists Inc., St. Paul, pp 415-472.

Cagampang GB, Perez CM, Juliano BO. 1973. A gel consistency test for eating quality of rice. J. Sci. Food Agric. 24: 1589-1594.

Cho YG, Kang YG, Lee YT, Jong SK, Eun MY, McCouch SR. 2011. Identification of quantitative trait loci for physical and chemical properties of rice grain. Plant Biotechnol. Rep. 4: 61-73.

Commuri PD, Keeling PL. 2001. Chain-length specificities of maize starch synthase I enzyme: studies of glucan affinity and catalytic properties. Plant J. 25: 475-486.

Day CD, Lee E, Kobayashi J, Holappa LD, Albert H, Ow DW. 2000. Transgene integration into the same chromosome location can produce alleles that express at a predictable level, or alleles that are differentially silenced. Genes 
Dev.14: 2869-2880.

Dian W, Jiang H, Wu P. 2005. Evolution and expression analysis of starch synthase III and IV in rice. J. Exp. Bot. 56: 623-632.

Fujita N, Satoh R, Hayashi A, Kodama M, Itoh R, et al. 2011. Starch biosynthesis in rice endosperm requires the presence of either starch synthase I or IIIa. J. Exp. Bot. 62: 48194831.

Fujita N, Yoshida M, Asakura N, Ohdan T, Miyao A, et al. 2006. Function and characterization of starch synthase I using mutants in rice. Plant Physiol. 140: 1070-1084.

Fujita N, Yoshida M, Kondo T, Saito K, Utsumi Y, et al. 2007. Characterization of SSIIIa-deficient mutants of rice: the function of SSIIIa and pleiotropic effects by SSIIIa deficiency in the rice endosperm. Plant Physiol. 144: 2009-2023.

Guan HP, Keeling PL. 1998. Starch Biosynthesis: Understanding the Functions and Interactions of Multiple Isozymes of Starch Synthase and Branching Enzyme.Trends Glycosci. Glyc. 10: 307-319.

Hawker JS, Ozbun JL, Ozaki H, Greenberg E, Preiss J. 1974. Interaction of spinach leaf adenosine diphosphate glucose alpha-1,4-glucan alpha-4-glucosyl transferase and alpha1,4-glucan, alpha-1,4-glucan-6-glycosyl transferase in synthesis of branched alpha-glucan. Arch. Biochem. Biophys. 160: 530-551.

Hirose T, Terao T. 2004. A comprehensive expression analysis of the starch synthase gene family in rice (Oryza sativa L.). Planta 220: 9-16.

Hsu YC, Tseng MC, Wu YP, Lin MY, Wei FJ, Hwu KK, Hsing YI, Lin YR. 2014. Genetic factors responsible for eating and cooking qualities of rice grains in a recombinant inbred population of an inter-subspecific cross. Mol. Breed. 34: 655-673.

James MG, Denyer K, Myers AM. 2003. Starch synthesis in the cereal endosperm. Curr. Opin. Plant. Biol. 6: 215-222.

Jeon JS, Ryoo N, Hahn TR, Walia H, Nakamura Y. 2010. Starch biosynthesis in cereal endosperm. Plant Physiol. Biochem. 48: 383-392.

Jiang H, Dian W, Liu F, Wu P. 2004. Molecular cloning and expression analysis of three genes encoding starch synthase II in rice. Planta 218: 1062-1070.

Juliano BO, Perez CM. 1983. Major factors affecting cooked milled rice hardness and cooking time. J. Texture Stud. 14: 235-243.
Lee HJ, Abdula SE, Jee MG, Jang DW, Cho YG. 2011. High-efficiency and Rapid Agrobacterium-mediated genetic transformation method using germinating rice seeds. J. Plant Biotechnol. 38: 251-257.

Lestari P, Ham TH, Lee HH, Woo MO, Jiang W. 2009. PCR markerbased evaluation of the eating quality of japonica rice (Oryza sativa L.). J. Agric. Food Chem. 57: 27542762.

Little RR, Hilder GB, Dawson EH. 1958. Differential effect of dilute alkali on 25 varieties of milled white rice. Cereal Chem. 35: 111-126.

Liu F, Makhmoudova A, Lee EA, Wait R, Emes MJ. 2009. The amylose extender mutant of maize conditions novel protein-protein interactions between starch biosynthetic enzymes in amyloplasts. J. Exp. Bot. 60: 4423-4440.

Liu F, Romanova N, Lee EA, Ahmed R, Evans M. 2012. Glucan affinity of starch synthase IIa determines binding of starch synthase I and starch-branching enzyme IIb to starch granules. Biochem. J. 448: 373-387.

Miki D, Shimamoto K. 2004. Simple RNAi vectors for stable and transient suppression of gene function in rice. Plant Cell Physiol. 45: 490-495.

Mu-Forster C, Huang R, Powers JR, Harriman RW, Knight M. 1996. Physical association of starch biosynthetic enzymes with starch granules of maize endosperm. Granule-associated forms of starch synthase I and starch branching enzyme II. Plant Physiol. 111: 821-829.

Myers AM, Morell MK, James MG, Ball SG. 2000. Recent progress toward understanding biosynthesis of the amylopectin crystal. Plant Physiol. 122: 989-997.

Nakamura Y, Francisco PB, Jr., Hosaka Y, Sato A, Sawada T. 2005. Essential amino acids of starch synthase IIa differentiate amylopectin structure and starch quality between japonica and indica rice varieties. Plant Mol. Biol. 58: 213-227.

Nakamura Y, Yuki K, Park SY, Ohya T. 1989. Carbohydrate metabolism in the developing endosperm of rice grains. Plant Cell Physiol. 30: 833-839.

Nishi A, Nakamura Y, Tanaka N, Satoh H. 2001. Biochemical and genetic analysis of the effects of amylose-extender mutation in rice endosperm. Plant Physiol. 127: 459-472.

Otani M, Hamada T, Katayama K, Kitahara K, Kim SH. 2007. Inhibition of the gene expression for granule-bound starch synthase I by RNA interference in sweet potato plants. Plant Cell Rep. 26: 1801-1807. 
Pandey MK, Rani NS, Madhav MS, Sundaram RM, Varaprasad GS, Sivaranjani AK, Bohra A, Kumar GR, Kumar A. 2012. Different isoforms of starch-synthesizing enzymes controlling amylose and amylopectin content in rice (Oryza sativa L.). Biotechnol. Adv. 30:1697-1706.

Pedersen JF, Bean SR, Funnell DL, Graybosch RA. 2004. Rapid iodine staining techniques for identigying the waxy phenotype in sorghum grain and waxy genotype in sorghuum pollen. Crop Sci. 44: 764-767.

Perez CM, Juliano BO. 1978. Modification of the simplified amylose test for milled rice. Starch 30: 424-426.

Stawski D. 2008. New determination method of amylose content in potato starch. Food Chem. 110: 777-781.

Sun MM, Abdula SE, Lee HY, Cho YC, Han LZ, Koh HJ, Cho YG. 2011. Molecular aspect of good eating quality formation in japonica rice. PLoS ONE 6(4): e18385. doi:10.1371/journal.pone. 0018385.

Takeda Y, Hizukuri S, Juliano BO. 1987. Structure of rice amylopectins with low and high affinity for iodine. Carbohydr. Res. 168: 79-88.
Tan YF, Li JX, Yu SB, Xing YZ, Xu CG. 1999. The three important traits for cooking and eating quality of rice grains are controlled by a single locus in an elite rice hybrid, Shanyou 63. Theor. Appl. Genet. 99: 642-648.

Tian Z, Qian Q, Liu Q, Yan M, Liu X, Yan C, Liu G, Gao Z, Tang S, Zeng D, Wang Y, Yu J, Gu M, Li J. 2009. Allelic diversities in rice starch biosynthesis lead to a diverse array of rice eating and cooking qualities. Proc. Natl. Acad. Sci. USA 106: 21760-21765.

Umemota T, Terashima K. 2002. Activity of granule-bound starch synthase is an important determinant of amylose content in rice endosperm. Funct. Plant Biol. 29: 11211124.

Wei C, Qin F, Zhu L, Zhou W, Chen Y. 2010. Microstructure and ultrastructure of high-amylose rice resistant starch granules modified by antisense RNA inhibition of starch branching enzyme. J. Agric. Food. Chem. 58: 1224-1232.

Yamanouchi H, Nakamura Y. 1992. Organ specificity of isoforms of starch branching enzyme (Q-Enzyme). Plant Cell Physiol. 33: 985-991. 